\title{
Perceived incidence of drug use in Australian sport: a survey of athletes and coaches
}

\author{
Stephen Moston \\ Centre for Applied Psychology, Faculty of Health, University of Canberra, ACT 2601, \\ Australia \\ E. Terry Engelberg \\ $\&$ \\ James Skinner \\ Department of Tourism, Sport and Hotel Management, Griffith Business School, Parklands \\ Drive, Gold Coast Campus, QLD, Australia
}

Contact author: Stephen Moston

Phone: (61 - 2 - 6201 5288)

Email: stephen.moston@canberra.edu.au 


\begin{abstract}
Doping control statistics suggest that only 1-2 per cent of athletes are doping. However, studies of the perceived incidence of doping, suggest that athletes believe that doping may be far more prevalent. Perceptions may potentially be of greater significance than actual incidence: athletes who believe that other athletes are doping may be more likely to engage in such practices, potentially creating a damaging self-fulfilling prophecy. This study investigated the perceptions of 609 Australian elite athletes and coaches about the extent of doping in sport. Data were collected via a self-completed survey. Results showed that the perceived incidence of performance enhancing drug use was approximately 19\% (30\% for perceived incidence of recreational drug use). Findings are discussed in relation to how perceptions might influence athletes through the creation of damaging self-fulfilling prophecies, and how sporting associations have attempted to control testing procedures to influence perceptions of drug use in sport.
\end{abstract}




\section{Introduction}

In psychology it is widely recognized that expectancies, both true and false, can create behavioural changes that ultimately lead to their own fulfilment, a process known a selffulfilling prophecy. Expectancies can affect both the perceiver (the person holding the expectancy) and the target (the person who is perceived). Merton (1948) offered the following definition:

The self-fulfilling prophecy is, in the beginning, a false definition of the situation evoking a new behavior which makes the originally false conception come true. The specious validity of the self-fulfilling prophecy perpetuates a reign of error. For the prophet will cite the actual course of events as proof that he was right from the very beginning. (p.195)

In the decades since Merton's work, there have been a large number of empirical studies on the mechanisms and power of self-fulfilling prophecies. False expectancies have proven to be a particularly important area of such research, in part because they have considerable potential for causing harm (Jussim, 1986), but also because they are often highly resistant to change (Miller \& Turnbull, 1986). It has been suggested (Rosenthal \& Jacobson, 1968) that self-fulfilling prophecies can create widespread social problems by accumulating over time: the magnitude of a perceiver's self-fulfilling prophecy becoming stronger as it is repeated and reinforced. It has also been argued (Madon, Willard, Guyll, \& Scherr, 2011) that accumulation also occurs when the number of people holding a false belief increases. A selffulfilling prophecy thus becomes increasingly likely when a false belief is repeated over time and/or widely shared. One social problem where such a process may be occurring is that of doping in sport. There are actually two main prophecies here.

The first, bluntly put, is that winners take drugs! The perception is that champions in many elite sports have achieved success through doping. In the case of track sprinting (100m), there is empirical evidence to suggest that performance enhancing drugs have not had any discernible impact on sprinting times and that the perceived impact of doping is in 
fact a myth (Hermann \& Henneberg, 2013). Nevertheless, there is a perception that an athlete who does not dope, is at a disadvantage and therefore unlikely to win.

The second, is that the public accepts, and possibly even demands, that elite athletes dope. The public appetite for records to be broken, places unrealistic expectations on athletes that can only be met through doping.

Together, these prophecies may assist in explaining why anti-doping efforts have largely failed to deter doping. The expectancies that elite athletes have about doping, together with their perceptions about how doping is perceived by sports’ stakeholders (coaches, administrators, supporters, etc.) are powerful pro-doping expectancies. An ambitious athlete then chooses doping as a means to achieve their goals.

This paper will explore the perceptions of athletes and coaches about doping in sport. In particular, it focuses on the perceived incidence of doping. Perceptions of doping may be of considerably greater importance than observed behaviours. It will be argued here that the objective measurement of doping, which is a somewhat spurious process, produces an estimated incidence of doping that bears little relation to the perceived incidence of such behaviour. While it is possible that perceptions might in fact be more accurate than 'objective' data suggests, the prophecies that doping is common and necessary, have been repeated and reinforced to such an extent that doping is becoming normalised. There is also limited evidence to suggest that the number of people holding such views is increasing.

We begin our analysis by briefly reviewing data from anti-doping controls, followed by data from incidence studies featuring athletes. We then examine perceptions about doping. The official version

Each year the World Anti-Doping Agency (WADA) acts as a central clearinghouse for data on analytical results by accredited anti-doping laboratories. In 2011 WADA accredited laboratories conducted a combined total of 243,193 analyses, with 'adverse' or 
'atypical' findings, found in 1.2\% of the cases (WADA, 2012a). An adverse or atypical finding is not the same as an adjudicated or sanctioned anti-doping rule violation, as some athletes may have had therapeutic use exemptions. The incidence of doping violations has generally been found to be less than half of one per cent. For example, in Australia in the reporting period 2011-12, the Australian Sports Anti-doping Authority (ASADA) conducted 7,196 biological tests of athletes, resulting in 33 athletes or support personnel being entered into the Register of Findings of anti-doping rule violations (ASADA, 2012). The incidence rate for doping violations in the period was thus $0.46 \%$. It is important to note that such data includes cases of both performance enhancing and recreational drug use combined, since both forms of drug use are part of the broad definition of doping.

Few regard such statistics as reliable measures of the true incidence of doping. As Mottram (2003) wrote: "These figures, which themselves may not be a true reflection of the truth, merely tell us how many athletes have tested positive, not how many are using drugs and avoiding detection” (p.357). Former WADA President Dick Pound acknowledged that the small number of athletes who are caught, was an under-estimation (Price, 2012). Asked to estimate the true incidence of doping, Pound said: "It's north of 10 and short of 90 [\%], but it's more than people expect".

Self-report surveys of drug use by athletes

Not surprisingly, asking athletes whether they have taken banned performance enhancing drugs or other illicit drugs is fraught with both ethical and methodological difficulties (Dimeo \& Taylor, 2013). The use of self-report surveys (Ama, Betnga, Moor, \& Kamga, 2003; Goulet, Valois, Buist, \& Cote, 2010; Ozdemir et al., 2005; Spence \& Gauvin, 1996; Thomas, Dunn, Swift, \& Burns, 2011), has been criticised (Mottram, 2011), yet attempts to develop alternative data collection procedures, such as randomized response techniques (Striegel, Simon, Hansel, Niess, \& Ulrich, 2006; Striegel, Ulrich, \& Simon, 2010) 
have typically fared little better. In large part, this is because studies, of all types, have used different definitions (e.g., 'doping’ vs. 'performance enhancing drug use’ vs. specific named substances, such as 'anabolic steroids') and types of question used (e.g., 'ever used’ vs. 'used in the last 12 months'). Despite the varied samples and methodologies, it is clear that the estimated incidence of drug use by athletes from surveys, which ranges from 1-39\% (Lentillon-Kaestner \& Ohl, 2011), typically exceeds the estimates from laboratory analyses. Athletes' perceptions of the incidence of drug use in sport

In the Sports Illustrated (2010) '9th Annual Players Survey’, 71 professional golfers were asked a series of questions about a range of issues relating to golf, politics and other issues. One of the questions was: 'Do you think Tiger [Woods] used HGH or other performance-enhancing drugs?' Twenty-four per cent said 'Yes'.

Surveys of perceived drug use by athletes are rarely ever so personalised. Instead, most surveys ask current athletes to estimate the perceived incidence of drug use in either their own sport, or across all sports (Jalleh \& Donovan, 2008; Thomas et al., 2011). One typical example is the survey of 706 English football (soccer) players byWaddington, Malcolm, Roderick, and Naik (2005). Nearly half (49\%) of the sample stated that no players used performance enhancing drugs; $23 \%$ of the sample stated that 'less than $2 \%$ ' of players were users; $8 \%$ said ' $3-5 \%$ '; and 3\% said 'more than 6\%'. The remaining members of the sample (17\%) had no opinion.Waddington et al. (2005) also reported that $6 \%$ of their sample knew players who used performance enhancing drugs, and 45\% knew players who used recreational drugs. An obvious limitation in such data is that a large number of athletes may be referring to knowledge of a single doping athlete. That is, ' $45 \%$ ' of athletes may all know the same single athlete who is using drugs.

Perceived incidence studies have been criticised for producing potentially inflated estimates (James, Nepusz, Naughton, \& Petróczi, 2013), and as such, the incidence figures 
that they have generated are generally not regarded as valid (Mottram, 2003). Despite this limitation, the data do reflect the 'doping climate' within the targeted population. As discussed earlier, perceptions (be they true or false), can shape the behaviour of both the perceiver and the target, potentially resulting in a potentially damaging self-fulfilling prophecy. In short, through a process of accumulation an initially false expectation may come to fulfilment.

The public's perceptions of the incidence of drug use in sport

While the perceptions held by elite athletes are of obvious relevance to the debate on doping, few have realised the potentially even more significant issue of the perceptions of key stakeholders in sport, most notably, the perceptions of the general public, the consumers of sport. A recent survey of Australian public opinion about doping in sport (Moston, Skinner, \& Engelberg, 2012) asked a large representative sample ( $\mathrm{n}=2520)$ to separately estimate the incidence of 'performance enhancing' and 'recreational' drugs use by athletes (terms were defined prior to each question being asked). The mean estimated incidence of performance enhancing drug use was $26 \%$. For recreational drugs the mean estimated incidence was 33\%. Respondents were asked to name a sport (unprompted) in which performance enhancing and recreational drugs were most commonly used. The sport that most participants perceived as having athletes who commonly use performance enhancing drugs was athletics (selected by $20.3 \%$ of respondents), followed by weight lifting, cycling, rugby league, Australian Football League (AFL) and swimming. For recreational drugs, the sports most commonly identified were AFL (selected by 35.3\% of respondents) and rugby league (selected by $31.6 \%$ of respondents).

In order to understand perceptions about doping, it is necessary to consider the likely sources of such information. If doping is relatively rare, then most athletes (and the public) 
will probably not have had any personal contact with a doping athlete. Instead, their perceptions will be shaped by other sources, most notably, the media.

The media and the creation of a moral panic

While official statistics suggest that doping is relatively is rare, over the last decade the media have nevertheless maintained an almost continuous series of accounts of doping in sport. Reporting is highly likely to be subject to common media distortions that rely on stereotypes. For example, demonised 'others’ (Hinds, 2009) such as Chinese swimmers are doping, but local swimmers are not. The media can set the agenda with regard to how policy makers respond to illegal behaviour, such as doping. The media can also create public anxiety about a problem (either a specific behaviour or group of people) resulting in what is known as a 'moral panic', a term used (Cohen, 1972) to describe: “a condition, episode, person or group of persons (that) emerges to become defined as a threat to societal values and interests” (p.9). The power of the media to generate panic can be illustrated by fears about problems (such as random violent crime) that may not actually exist in Australia, and ironically may only barely exist in the USA where the panic originated (Israel \& Schwartz, 2000). A succession of doping stories in the media might give rise to distorted beliefs about the prevalence of such behaviour, possibly even unfairly tarnishing certain sports. The present study

The present study seeks to determine the perceived incidence of both performance enhancing and recreational drug use amongst a sample of elite Australian athletes. There are two important reasons for such a study.

First, if athletes perceive that the majority of their competitors are doping, then they may be more likely to engage in such behaviour. This would fulfil the initial prophecy. Estimates of incidence reflect the prevailing climate of doping in sport. It is worth noting here that the revelation that Canadian sprinter Ben Johnson had been using banned substances 
when he won Olympic Gold was initially expected to serve as a deterrent to other athletes. Instead, the Ben Johnson case may have had exactly the opposite effect. Instead of focussing on the fact that Johnson was eventually caught and punished, some noted only that he had won. Johnson’s former coach, Charlie Francis, summarised the beneficial effects of doping when he said: "It's pretty clear that steroids are worth the price of a metre at the highest levels of sport” (Verroken, 2000).

Second, the opinions and attitudes of athletes about a range of drug use in sport issues might serve as indirect clues to possible drug use. Studies (Skinner, Moston, \& Engelberg, 2011; Wolfson, 2000) have shown that people who are using drugs tend to offer higher estimates of such drug use amongst similar others, than people who are not using such drugs. Another study (Petróczi, Mazanov, Nepusz, Backhouse, \& Naughton, 2008) found that athletes who used performance enhancing drugs offered much higher incidence estimates than non-users (35.11\% vs. 15.34\%). This behaviour is usually explained in terms of a psychological process called the 'false consensus effect’ (Ross, Greene, \& House, 1977) which occurs when individuals tend to overestimate the "extent to which others behave the same way as they do, especially if the behaviour in question is deemed to be socially questionable or unacceptable” (Petróczi et al., 2008). Incidence estimates can thus serve as a possible proxy for inferring drug use, possibly directing scarce anti-doping resources towards the sports and athletes most likely to be doping, or at risk of doping.

The study sought to directly compare the perceptions of both athletes and coaches. While athletes are legally responsible for the decision to dope, the decision to dope will in all likelihood have been shaped by a number of potentially significant referent groups. For elite adult athletes, the coach is the most powerful source of influence (Backhouse \& McKenna, 2012). This may be through an explicit instruction, or an implicit suggestion, perhaps through the setting of unrealistic goals for training or performance. The role of coaches in the decision 
to dope has not been widely studied, however, athletes who said their coaches frequently criticised them, punished them for mistakes, encouraged rivalries and gave unequal recognition to team-mates had the most favourable attitudes towards doping (Aldhous, 2008). However, other research (Kirby, Moran, \& Guerin, 2011) has found that the role of coaches in shaping doping attitudes and behaviors is relatively limited, suggesting instead that both personal characteristics and the attitudes of team mates might be more significant. This study will add to this ongoing debate by comparing the views of athletes and coaches, identifying issues where there is a convergence and divergence of opinion.

In addition to asking participants to estimate the incidence of drug use in sport, the study also examines which sports are most readily identified with doping (both performance enhancing and recreational drug use). According to the latest WADA statistics (WADA, 2012b), the sports with the highest numbers of adverse analytical findings (blood and urine tests combined) are weightlifting (93 cases), athletics (39 cases), cycling (25 cases) and rugby (15 cases). In Australia, anti-doping control statistics (ASADA, 2012) reveal that the sports with the highest numbers of adverse findings are rugby union and bodybuilding ( 4 cases each), rugby league (3 cases), Australian rules football, cycling and powerlifting (2 cases each). We are not aware of any data on the frequency with which media reports feature cases of doping, although the sports of cycling (performance enhancing drug use) and rugby league and Australian rules football (both recreational drug use) are most probably those with the highest levels of media coverage. The sport of weightlifting receives very little coverage in the Australian media, even when the stories are about doping. It is hypothesised that perceptions of doping, in this case the identification of sports associated with doping, will more closely reflect the media's reporting bias rather than official anti-doping control statistics. 


\section{Method}

Sample

The sample comprised 609 elite athletes and coaches from the Australian State of Queensland. There were 488 athletes (80.1\%) and 92 coaches (15.1\%). Sporting role was not specified by 29 respondents (4.8\%).The mean age of the sample was 26.4 years ( $S D$ 10.45). The mean age for the athletes was 24.2 years and for the coaches it was 37.8 years. There were 459 males (75.4\%) and 121 females (19.9\%). Gender was not specified by 29 respondents (4.8\%).

Respondents were asked to indicate whether they were competing or coaching at a regional, state, or national level. Unfortunately this classification scheme proved to be somewhat unreliable. Some athletes and coaches were unsure as to how they should classify their level of competition. This problem was first identified during face-to-face data collection, when a member of a professional team (a rugby league player) asked about how to classify his status. The logical response was 'national', but the athlete considered himself to be a regional player. Discussions with the other players in the team and subsequent data checking revealed that nearly all the players in that team had (incorrectly) identified themselves as 'regional' athletes. As a consequence, this demographic was not used in the subsequent data analysis.

Athlete respondents were asked whether they had ever been tested by anti-doping authorities. Coaches were asked in any of their athletes had been tested. Just under half of the respondents ( $\mathrm{n}=274 ; 45 \%)$ had never been tested; 9.2\% $(\mathrm{n}=56)$ had been tested once; and $38.6 \%(n=235)$ had been tested more than once. Some respondents $(n=44 ; 7.2 \%)$ did not answer this question.

Main sports represented (each more than 2\% of the sample) included: Australian football league (AFL: $15.1 \%$ of respondents), athletics (2.6\%), cycling (3.4\%), football 
(soccer) (14.9\%), rowing (2.8\%), rugby league (16.1\%), rugby union (9.9\%), surf lifesaving (5.9\%). The remaining 29.3\% respondents were from as 'other sports' (comprising baseball, basketball, boxing, canoeing/kayaking, cricket, gridiron, hockey, ice hockey, ice skating, karate, netball, roller derby, softball, swimming, table tennis, taekwondo, tennis, touch football, triathlon, volleyball, water polo, weightlifting, and yachting).

\section{Instrument}

A survey questionnaire was created to explore the perceptions of the incidence of doping. The questionnaire was based on previous incidence research (Moston et al., 2012). Throughout the survey a distinction was made between performance enhancing (banned) substances and illicit 'recreational' drugs. Perceptions of use of substances such as sport supplements, alcohol or tobacco were not assessed. The questions were organised into the following main sections:

Perceptions of drug use in sport

Respondents were asked to estimate the percentage of elite athletes (all sports, and own sport) using both performance enhancing and recreational drugs. They were also asked to identify sports (open questions, no prompts given) in which the use of each category of drugs was perceived to be commonly used. Respondents were asked to name one sport only for each category of doping (performance enhancing, recreational).

\section{Respondent demographics}

In addition to the above questions, the following demographic details of the respondents were gathered: sex, age, main sport in which respondent competed or coached, history of anti-doping testing, and highest level of competition at which they had competed or coached sport. 


\section{Procedure}

The survey was produced in two formats: an online, web-based format hosted by SurveyMonkey ${ }^{1}$ and a printed version. The printed version consisted of a booklet that respondents could complete by hand. The content of both versions was identical. Almost half (47\%; $n=285$ ) of respondents completed the survey online and the remaining respondents ( $n=324 ; 53 \%)$ completed the printed version of the survey. Screening checks were conducted to compare the responses from each data collection modality (e.g., frequency estimates by modality). All comparisons were non-significant and consequently all data were collapsed into a single source for analysis.

\section{Recruitment strategy}

A list of all State Sporting Organisations (SSOs) in the State of Queensland was obtained from the Queensland Government, Department of Communities, Sport and Recreation website $^{2}$. An additional list of all professional sporting clubs based in Queensland was compiled. A letter or email was sent to a senior officer (e.g., President, Secretary) of each of the clubs/SSOs that met our criteria (governing body of a competitive sport for athletes aged 18 and above). Clubs and organisations that did not meet these criteria (e.g., junior and non-competitive sports) were excluded. The letter/email consisted of a request to each organisation to invite their athletes and coaches to participate in a survey of attitudes towards doping in sport. The letter/email stated that the survey was available on either an electronic version (an electronic link was included), or printed copies could be posted to the SSO for distribution.

The first message to clubs/SSOs was followed by reminders sent approximately 4 and 6 weeks later. Many SSOs cooperated by including a link to the survey in their webpages or

\footnotetext{
${ }^{1}$ https://www.surveymonkey.com

${ }^{2}$ http:// www.sportrec.qld.gov.au/Industryinformation/Industrycontacts/Statesportandrecreation organisations.aspx
} 
by distributing details of the survey through their membership mailing lists. Clubs typically invited the researchers to make personal visits to the clubs (for example, after training), so that athletes and coaches could complete a printed version of the survey. During these visits, a member of the research team introduced the study and stated that participation was voluntary; that all data collected would be anonymous; and that data from teams and individuals would not be identifiable. All respondents were instructed to complete the surveys individually.

\section{Data collection evaluation}

The combination of recruitment methods was successful, although extremely timeconsuming. Our experiences matched many of those detailed by other researchers such as Dunn et al. (2009). The explanations given for non-cooperation were varied. One professional rugby team was simply 'not interested'; one SSO said their athletes were 'overstudied' as they participated in a large number of 'similar' research studies (although we could find no evidence of any participation in anti-doping studies). Despite these challenges, the vast majority of elite sporting clubs (including nearly all the professional teams in Queensland) and SSOs cooperated with the researchers. Due to the differences in structure of elite sport it was not possible to generate an estimate of the size of the total population of elite athletes. Consequently, we cannot estimate the response rate for the study. Despite these problems, the researchers personally collected data from the vast majority of elite clubs in the state, suggesting that the sample was representative.

\section{Results}

Perceived incidence of drug use

Athletes and coaches were first asked to estimate the incidence of performance enhancing/recreational drug use across all sports, and then for their own sports. The overall mean estimated incidence for performance enhancing drug use in all sports was $18.75 \%$, and 
for recreational drug use it was $29.76 \%$. The overall estimates for usage within the respondents' own sport were considerably lower, at 9.85\% and 23.16\% respectively for each type of drug use (average across all respondents). There were no significant differences ( $t$ tests) between the views of the athletes and coaches on any of these four estimates of incidence (all comparisons $\mathrm{p}>.05$ ).

\section{INSERT TABLE 1 ABOUT HERE}

For estimates of performance enhancing drug use in all sports, only a small number of athletes and coaches (12.0\%) offered incidence estimates for performance enhancing drug use of $2 \%$ or less (an estimate that would be accordance with official anti-doping control statistics. The remaining participants (88.0\%) gave higher estimates. Almost half (45.4\%) offered estimates of $11 \%$ or higher. A small percentage of participants (6.9\%) estimated incidence at $50 \%$ or higher.

For estimates of performance enhancing drug use in own sport, the pattern of results was quite different to that seen for all sports. For own sport $11.9 \%$ suggested that no athletes were using performance enhancing drugs, and 30.1\% offered incidence estimates in line with official doping statistics (i.e., 1-2\%). Only 18.8\% estimated incidence at higher than $10 \%$ in their own sport.

For illicit recreational drugs (all sports), nearly all estimates (96.1\%) exceeded the data from official doping control statistics, but within the participants' own sport, the comparable figure dropped to $89.5 \%$.

\section{INSERT TABLE 2 ABOUT HERE}

The perceived incidence of performance enhancing and recreational drugs in the participant's own sport was then examined for each of the main sports represented in the study (see Table 3). In Table 3 only sports with at least 15 participants each (athletes and 
coaches combined) appear separately. Data for respondents in all other sports are collapsed into "Other sports".

\section{INSERT TABLE 3 ABOUT HERE}

Table 3 shows that the sport with the highest self-perceived incidence of performance enhancing drug use was cycling (estimated at 33.3\%). At the other extreme, perceived performance enhancing drug use in AFL was very low (estimated at only 3.8\%). For recreational drug use the sport with the highest self-perceived incidence was rugby union (estimated at 31.4\%), with rowing offering the lowest incidence estimates (11.5\%).

Further examination of the data from the study revealed that the majority of athletes and coaches (74.1\%) estimated that performance enhancing drug use was higher in all sports, compared to their own. Almost a fifth (18.1\%) saw their own sport as equivalent to other sports, with the remainder (7.8\%) actually seeing their own sport as worse than other sports.

The majority of respondents $(n=443,74.1 \%)$ estimated that performance enhancing drug use was higher in all other sports, compared to their own. 108 (18.1\%) respondents offered equivalent estimates for all sports and within their own sport. A minority ( $n=47$, 7.8\%) estimated that performance enhancing drug use was higher in their own sport than across all other sports.

Identification of sports in which drug use is common

For all respondents combined, the top three sports in which performance enhancing drugs were seen as being most commonly used included weightlifting, cycling, and athletics (see Table 4). Other sports identified by less than $2 \%$ of respondents included: Australian rules football boxing, American Football; cricket; rowing; basketball, football (soccer), gymnastics, karate, rugby union, surfing, water polo, and yachting.

INSERT TABLE 4 ABOUT HERE 
Sports in which recreational drugs were seen as being most commonly used included rugby league, surfing and AFL (see Table 5). Other sports identified by less than $2 \%$ of respondents included: basketball; cycling; weightlifting; boxing; athletics; swimming; baseball; yachting; American Football; archery; cricket, hockey, judo, netball, taekwondo, tennis, volleyball, water polo, and ice hockey.

\section{INSERT TABLE 5 ABOUT HERE}

\section{Discussion}

The estimated incidence of both performance enhancing and recreational drug use in the current study far exceeds the incidence estimates from biological testing. The overall estimated incidence for performance enhancing drugs was $18.75 \%$, with the sports of weightlifting, cycling and athletics identified as those in which usage was highest. Athletes and coaches from the sport of cycling estimated that performance enhancing drug use within their own sport was 33.3\%. The cyclists thus endorse the negative perception of their own sport.

For recreational drug use the overall estimated drug use was $29.76 \%$, with the sports of rugby league, surfing and AFL identified as those where incidence was highest. Rugby union players and coaches estimated the incidence of recreational drug use within their own sport as 31.4\% (confirming the overall negative perceptions of their sport), whilst AFL players and coaches estimated the incidence of recreational drug use within their own sport at 17.3\%. The majority of athletes and coaches estimated that performance enhancing drug use was higher in all sports, compared to their own. Just under $8 \%$ of athletes saw their own sport as having a higher incidence of performance enhancing drug use relative to all sports.

While it is impossible to verify the accuracy of such perceptions, these findings nevertheless have important implications for how anti-doping campaigns are run, and also possibly for detecting doping in sport. First, in terms of the prophecies about doping in sport, 
the data from this study suggests that doping (both performance enhancing and recreational drug use) is perceived to be relatively common in sport: a view is held by the majority of athletes and coaches. For example, the vast majority of participants offered estimates of performance enhancing drug use that were far higher than the official statistics would suggest (i.e., 1-2\%). As Madon et al. (2011) suggest, a belief that is shared by large number of people (even a false belief), may lead to the creation of a self-fulfilling prophecy. A concern here is that if athletes and their coaches perceive that a large number of competitors are doping then they may be more likely to similarly engage in such behaviour. It is not necessary for these athletes and coaches to believe that the majority are doping, rather, a perception that the majority of winners are doping that will ultimately guide their behaviour. This would fulfil the prophecy.

Second, the results are an indirect clue to possible drug use by individuals. Studies (Petróczi et al., 2008; Skinner et al., 2011) have shown that people who are using drugs tend to offer higher estimates of drug use than non-users. This 'false consensus effect' (Ross et al., 1977) occurs when individuals overestimate the "extent to which others behave the same way as they do. According to this principle, athletes who are using drugs are likely to overestimate the extent to which similar others (i.e., other users) behave as they do. Given that estimates of the incidence of drug use are not commonly known, and doping control statistics are an unreliable guide, athletes must estimate incidence based on their own experiences and media reports. Consequently, estimates that are clearly higher or lower than the norms of their peer group, may assist in detecting both users and non-users. The possible forensic role of such questions is only slowly beginning to be recognised (Stipis, 2010). It may be possible to identify doping athletes through their responses to questions about doping, such as perceptions of incidence. Forensic interviewing techniques, such as the Reid model of 
interviewing and interrogation, have long made use of similar questions to aid in the identification of suspects in criminal investigations (Inbau, Reid, Buckley, \& Jayne, 2001).

If the majority of athletes and coaches do see performance enhancing drug use as relatively prevalent, but not within their own sport, campaigns against doping will attract limited support from those people. Anti-doping campaigns will need to directly address these pre-conceptions, possibly by pointing out that across all the sports featured in this study that the incidence of drug use is in all likelihood higher than official estimates would suggest. For several sports that are not typically associated with high levels of performance enhancing drug use (football, rugby league, rugby union, surf lifesaving), estimates of incidence were about one in ten (roughly equivalent to 1-3 players per squad).

Overall, the estimates of drug use by athletes and coaches were slightly lower than the estimates offered by the Australian general public (Moston et al., 2012). However, if anything, the pattern of results for athletes/coaches and the general public showed a considerable degree of similarity, with both populations nominating similar selections for sports where both performance enhancing and recreational drug use are common. In short, the negative public perceptions of drug use in sport were largely echoed by the athletes and coaches featured in this study.

In terms of understanding the factors that might explain the divergent perceptions of doping, the media appears to play an inconsistent role. Official statistics (WADA, 2012b) suggest that the three sports where 'doping' occurs are weightlifting, athletics and cycling. In this study, the participants identified weightlifting, cycling and athletics as sports in which performance enhancing drug use was most common; with rugby league, surfing and Australian rules football nominated for recreational drug use. For performance enhancing drug use, the perceptions of the athletes and coaches in this study were thus in accordance with anti-doping control statistics and did not suggest an obvious impact of the media. 
However, for recreational drug use the finding suggest a stronger role for the media in shaping expectancies.

Overall, the study found no statistically significant differences in the opinions of athletes and coaches. This suggests that both groups are equally informed (or equally biased) in their perceptions of the prevalence of doping. The lack of divergence in views suggests that the content of anti-doping campaigns need not differ for each population, at least not on this issue.

\section{Conclusion}

Whilst there is no accurate way to assess the true incidence of drug use in sport, athletes and coaches perceive that such banned behaviour is highly prevalent. In many ways, this perception is a far greater threat to the integrity of sport than the actual incidence of drug use. If athletes and coaches perceive that performance enhancing drug use is common, then they will be more likely to adopt a similar strategy, possibly justifying such actions as 'levelling the playing field'. The danger here is that perceptions may shape reality, such that the initial prophecies about doping in sport will become self-fulfilling. For anti-doping campaigners this is a particularly alarming prospect as it suggests that doping is already so prevalent and normalised that its use will both persist and probably intensify. A different prophecy is required: perhaps, that doping athletes will be detected.

An additional problem is that a majority of athletes and coaches perceive that drug use is more common in sports other than their own, this may negate the impact of educational campaigns (athletes and coaches are effectively 'in denial'). The present study shows that in all the sports featured, the perceived incidence of drug use was considerably higher than the data from biological tests would suggest. The results also show that perceptions of performance enhancing and recreational drug use differ across sports, suggesting that anti- 
doping campaigns could be tailored to reflect the specific forms of doping associated with each sport, rather than a generic 'one-model-fits-all' campaign. 


\section{Tables}

Table 1: Perceived incidence of drug use in all sports and in own sport

Table 2: Frequency of estimates of perceived incidence of drug use in all sports and own sport

Table 3: Perceived incidence of drug use by sport

Table 4: Sports in which performance enhancing drugs are perceived to be commonly used Table 5: Sports in which recreational drugs are perceived to be commonly used 
Table 1: Perceived incidence of drug use in all sports and in own sport

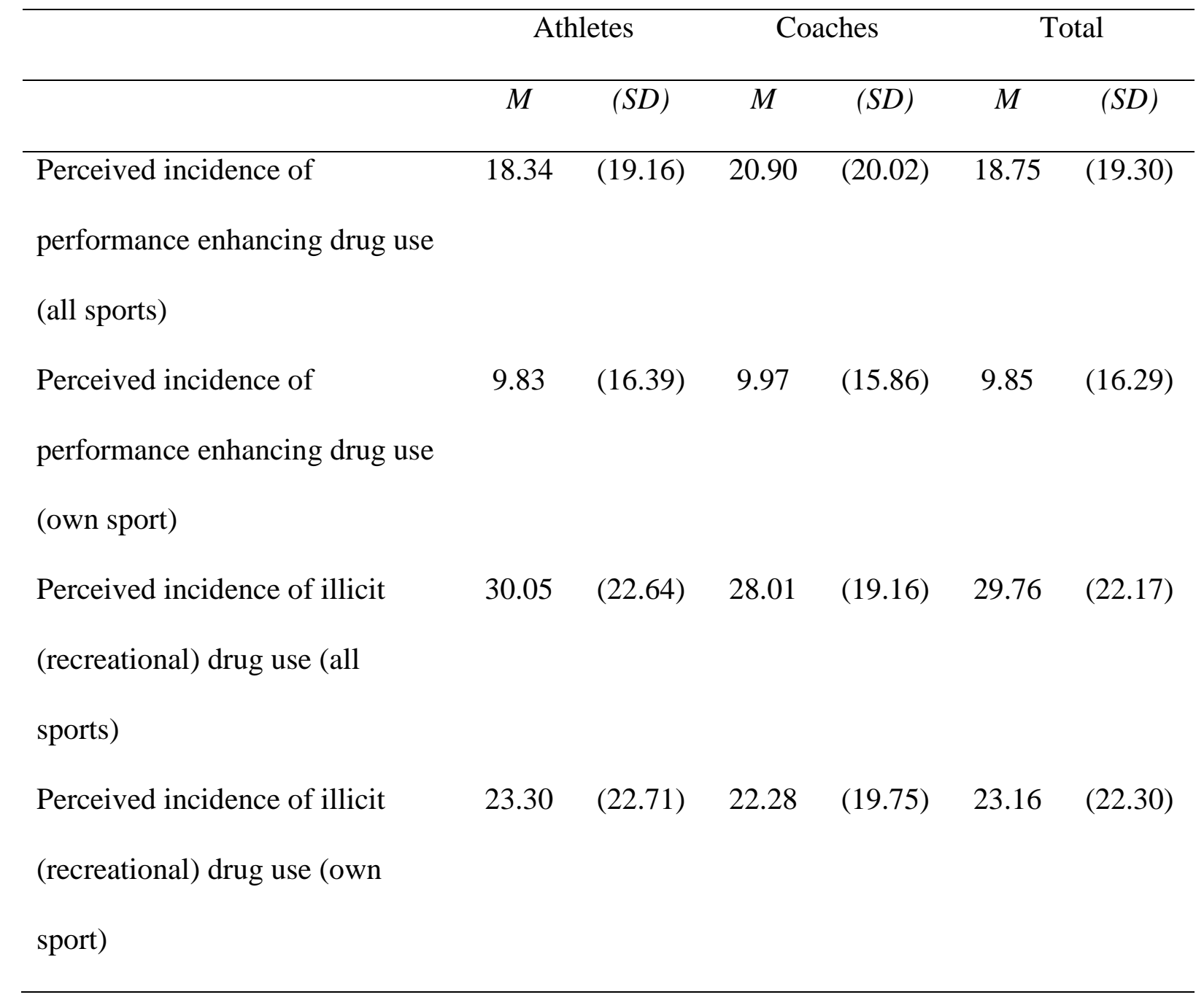


Table 2: Frequency of estimates of perceived incidence of drug use in all sports and own sport

\begin{tabular}{|c|c|c|c|c|}
\hline $\begin{array}{l}\text { Incidence } \\
\text { estimate } \\
\text { (\%) }\end{array}$ & $\begin{array}{c}\text { Perceived } \\
\text { incidence of } \\
\text { performance } \\
\text { enhancing drug } \\
\text { use (all sports) }\end{array}$ & $\begin{array}{c}\text { Perceived } \\
\text { incidence of } \\
\text { performance } \\
\text { enhancing drug } \\
\text { use (own sport) }\end{array}$ & $\begin{array}{c}\text { Perceived } \\
\text { incidence of illicit } \\
\text { (recreational) } \\
\text { drug use (all } \\
\text { sports) }\end{array}$ & $\begin{array}{c}\text { Perceived } \\
\text { incidence of illicit } \\
\text { (recreational) } \\
\text { drug use (own } \\
\text { sport) }\end{array}$ \\
\hline & \multicolumn{4}{|c|}{ Percentage of athletes and coaches (combined) offering estimate } \\
\hline 0 & 1.8 & 11.9 & 0.9 & 2.4 \\
\hline $1-2$ & 10.2 & 30.1 & 3.0 & 8.1 \\
\hline $3-10$ & 42.6 & 39.1 & 24.2 & 37.8 \\
\hline $11-20$ & 16.7 & 8.0 & 20.1 & 15.0 \\
\hline $21-30$ & 11.6 & 4.1 & 15.9 & 11.3 \\
\hline $31-40$ & 5.6 & 1.8 & 11.1 & 6.5 \\
\hline $41-50$ & 4.6 & 1.2 & 9.4 & 8.0 \\
\hline $51-60$ & 2.5 & 0.9 & 6.5 & 3.7 \\
\hline $61-70$ & 1.4 & 0.7 & 3.9 & 2.4 \\
\hline $71-80$ & 2.1 & 1.1 & 3.5 & 3.3 \\
\hline $81-90$ & 0.4 & 0.5 & 1.3 & 0.9 \\
\hline $91-100$ & 0.5 & 0.5 & 0.4 & 0.6 \\
\hline Means & 18.34 & 9.83 & 30.05 & 23.30 \\
\hline
\end{tabular}


Table 3: Perceived incidence of drug use (by sport)

\begin{tabular}{lccc}
\hline $\begin{array}{l}\text { Athletes' and Coaches' } \\
\text { Own Sport }\end{array}$ & $\mathrm{N}$ & $\begin{array}{c}\text { Perceived incidence of } \\
\text { performance enhancing } \\
\text { drug use (\%) in own } \\
\text { sport }\end{array}$ & $\begin{array}{c}\text { Perceived incidence of } \\
\text { illicit (recreational) drug } \\
\text { use (\%) in own sport }\end{array}$ \\
\hline AFL & 89 & 3.8 & 17.3 \\
Athletics & 16 & 16.0 & 13.1 \\
Cycling & 21 & 33.3 & 23.7 \\
Football (soccer) & 84 & 9.2 & 25.4 \\
Rowing & 17 & 4.5 & 25.1 \\
Rugby league & 95 & 9.1 & 31.4 \\
Rugby union & 57 & 13.2 & 24.8 \\
Surf life saving & 36 & 10.1 & 2.4 \\
Other sports & 178 & 9.6 & \\
\hline
\end{tabular}


Table 4: Sports in which performance enhancing drugs are perceived to be commonly used (all participants)

\begin{tabular}{lcc}
\hline Sport & Number of participants & Percentage of participants \\
\hline Weightlifting & 178 & 29.2 \\
Cycling & 171 & 28.1 \\
Athletics & 123 & 20.2 \\
Rugby league & 49 & 8.0 \\
Baseball & 27 & 4.4 \\
Swimming & 16 & 2.6 \\
\hline
\end{tabular}


Table 5: Sports in which recreational drugs are perceived to be commonly used (all participants)

\begin{tabular}{lcc}
\hline Sport & Number of participants & Percentage of participants \\
\hline Rugby league & 262 & 43.0 \\
Surfing & 107 & 17.6 \\
AFL & 98 & 16.1 \\
Football (soccer) & 17 & 2.8 \\
Rugby union & 13 & 2.1 \\
\hline
\end{tabular}




\section{Acknowledgements}

This paper is based on the study “Athletes’ and Coaches’ Attitudes about Drugs in Sport”

which was supported by the Australian Government Department of Health and Ageing through the Anti-Doping Research Program. 


\section{References}

Aldhous, P. New Scientist. (2008). Inside the Minds of Athletes who Cheat. New Scientist, August(2667), 8-9.

Ama, P.F.M., Betnga, B., Moor, V.J.A., \& Kamga, J.P. (2003). Football and doping: study of African amateur footballers. British Journal of Sports Medicine, 37(4), 307-310. doi: 10.1136/bjsm.37.4.307

ASADA, Australian Sports Anti-doping Authority. (2012). 2011:12 Annual Report. Canberra, Australia: Australian Sports Anti-doping Authority

Backhouse, S.H., \& McKenna, J. (2012). Reviewing coaches' knowledge, attitudes and beliefs regarding doping in sport. International Journal of Sports Science \& Coaching, 7(1), 167-175. doi: 10.1260/1747-9541.7.1.167

Cohen, S. (1972). Folk Devils and Moral Panics: The Creation of the Mods and Rockers. Deviant Behavior, 4(1), 119-120.

Dimeo, Paul, \& Taylor, John. (2013). Monitoring drug use in sport: The contrast between official statistics and other evidence. Drugs: Education, Prevention \& Policy, 20(1), 40-47. doi: 10.3109/09687637.2012.713412

Dunn, M., Thomas, J. O., Burns, L., Swift, W., Price, K., \& Mattick, R. P. (2009). Attitudes Toward, Knowledge of, and Prevalence of Illicit Substance Use in Australia: First Results. University of New South Wales, Sydney: National Drug and Alcohol Research Centre.

Goulet, C., Valois, P., Buist, A., \& Cote, M. (2010). Predictors of the Use of PerformanceEnhancing Substances by Young Athletes. Clinical Journal of Sport Medicine, 20(4), 243-248. doi: 10.1097/JSM.0b013e3181e0b935

Hermann, A., \& Henneberg, M. (2013). The Doping Myth: 100m sprint results are not improved by 'doping'. International Journal of Drug Policy, 24(2), 110-114. doi: 10.1016/j.drugpo.2012.06.010

Hinds, Lyn. (2009). Media and crime. In H. P. T. Hayes (Ed.), An introduction to crime and criminology (pp. 3-17): Frenchs Forest, NSW: Pearson Education Australia, 2009.

Inbau, F. E., Reid, J. E., Buckley, J. P., \& Jayne, B. C. (2001). Criminal interrogation and confessions.

Israel, Mark, \& Schwartz, Martin D. (2000). Born in the USA : importing American fears of random crime (Vol. 11, pp. 337-342).

Jalleh, G., \& Donovan, R. (2008). Survey of Australian Elite Athletes’ Attitudes Towards and Beliefs about Sport Issues. Perth: Social Marketing Research Unit, School of Marketing, Curtin University.

James, R.A., Nepusz, T., Naughton, D.P., \& Petróczi, A. (2013). A potential inflating effect in estimation models: Cautionary evidence from comparing performance enhancing drug and herbal hormonal supplement use estimates. Psychology of Sport and Exercise, 14(1), 84-96. doi: 10.1016/j.psychsport.2012.08.003

Jussim, Lee. (1986). Self-fulfilling prophecies: A theoretical and integrative review. Psychological Review, 93(4), 429-445. doi: 10.1037/0033-295X.93.4.429

Kirby, K., Moran, A., \& Guerin, S. (2011). A qualitative analysis of the experiences of elite athletes who have admitted to doping for performance enhancement. International Journal of Sport Policy, 3(2), 205-224.

Lentillon-Kaestner, V., \& Ohl, F. (2011). Can we measure accurately the prevalence of doping? Scandinavian Journal Of Medicine \& Science In Sports, 21(6), e132-e142. doi: 10.1111/j.1600-0838.2010.01199.x 
Madon, S., Willard, J., Guyll, M., \& Scherr, K.C. (2011). Self-fulfilling prophecies: Mechanisms, power, and links to social problems. Social and Personality Psychology Compass, 5(8), 578-590. doi: 10.1111/j.1751-9004.2011.00375.x

Merton, R.K. (1948). The self-fulfilling prophecy. Antioch Review, 8, 193-210.

Miller, D.T., \& Turnbull, W. (1986). Expectancies and interpersonal processes. Annual Review of Psychology, 37, 233-256. doi: 10.1146/annurev.ps.37.020186.001313

Moston, S., Skinner, J., \& Engelberg, T. (2012). Perceived incidence of drug use in Australian sport: A survey of public opinion. Sport in Society, 15(1), 64-77. doi: 10.1080/03031853.2011.625277

Mottram, D.R. (2003). Prevalence of Drug Misuse in Sport. In D. Mottram (Ed.), Drugs in Sport. Milton Park, UK: Routledge.

Mottram, D.R. (2011). Prevalence of drug misuse in sport. In D. R. Mottram (Ed.), Drugs in sport (5th ed.). (pp. 373-385). New York, NY US: Routledge/Taylor \& Francis Group.

Ozdemir, L., Nur, N., Bagcivan, I., Bulut, O., Sumer, H., \& Tezeren, G. (2005). Doping and performance enhancing drug use in athletes living in Sivas, mid-Anatolia: A brief report. Journal of Sports Science and Medicine, 4(3), 248-252.

Petróczi, A., Mazanov, J., Nepusz, T., Backhouse, S.H., \& Naughton, D.P. (2008). Comfort in big numbers: Does over-estimation of doping prevalence in others indicate selfinvolvement? Journal of Occupational Medicine and Toxicology, 3, 19.

Price, S.L. (2012, 10 August). A doping free Olympics? Not in London - and maybe never, Sports Illustrated. Retrieved from http://sportsillustrated.cnn.com/2012/olympics/2012/writers/sl_price/08/10/2012olympics-doping/index.html\#ixzz2M3Jd4lc7

Rosenthal, R., \& Jacobson, L. (1968). Pygmalion in the classroom: Teacher expectation and pupils' intellectual development. New York: Holt, Rinehart, \& Winston.

Ross, L., Greene, D., \& House, P. (1977). The false consensus effect: An egocentric bias in social perception and attribution processes. Journal of Experimental Social Psychology, 13(3), 279-301.

Skinner, J., Moston, S., \& Engelberg, T. (2011). The Final Frontier of Anti-Doping: A Study of Athletes who have Committed Doping Violations. Final Report to the Department of Health and Ageing. Gold Coast, Australia: Griffith University.

Spence, J.C., \& Gauvin, L. (1996). Drug and Alcohol Use by Canadian University Athletes: A National Survey. Journal of Drug Education, 26, 275-287. doi: 10.2190/V8KUCW0L-WAQH-1D3A.

Sports Illustrated. (2010, 3 May). 9th Annual PGA Tour Players Survey, Sports Illustrated. Retrieved from http://sportsillustrated.cnn.com/vault/article/magazine/MAG1168986/index.htm

Stipis, C. (2010). The use of forensic interviewing in the fight against doping in sport. (Masters in Forensic Psychology), James Cook University, Townsville, Australia.

Striegel, H., Simon, P., Hansel, J., Niess, A. M., \& Ulrich, R. (2006). Doping and Drug Use in Elite Sports: An Analysis Using the Randomized Response Technique. Medicine and Science in Sports and Exercise, 38(5), S247-S247. doi: 10.1249/00005768200605001-01087

Striegel, H., Ulrich, R., \& Simon, P. (2010). Randomized response estimates for doping and illicit drug use in elite athletes. Drug and Alcohol Dependence, 106(2-3), 230-232. doi: 10.1016/j.drugalcdep.2009.07.026

Thomas, J.O., Dunn, M., Swift, W., \& Burns, L. (2011). Illicit drug knowledge and information-seeking behaviours among elite athletes. Journal of Science and Medicine in Sport, 14(4), 278-282. doi: 10.1016/j.jsams.2011.02.001 
Verroken, M. (2000). Drug use and abuse in sport. Baillière's Best Practice \& Research. Clinical Endocrinology \& Metabolism, 14(1), 1-23.

WADA, World Anti-Doping Agency. (2012a). 2011 laboratory testing figures. . Montreal: WADA Retrieved from http://www.wada-ama.org/Documents/Resources/TestingFigures/WADA-2011-Laboratory-Testing-Figures.pdf.

WADA, World Anti-Doping Agency. (2012b). 2012 Anti-Doping Testing Figures Report. Montreal: WADA Retrieved from http://www.wadaama.org/Documents/Resources/Testing-Figures/WADA-2012-Anti-Doping-TestingFigures-Report-EN.pdf.

Waddington, I., Malcolm, D., Roderick, M., \& Naik, R. (2005). Drug use in English professional football. British Journal Of Sports Medicine, 39(4), e18. doi: 10.1136/bjsm.2004.012468

Wolfson, S. (2000). Students' estimated of the prevalence of drug use: Evidence for a false consensus effect. Psychology of Addictive Behaviours, 14(3), 295-298. 